\title{
Incidence, Etiology and Risk Factors Associated with Mortality of Nosocomial Candidemia in a Tertiary Care Hospital in Istanbul, Turkey
}

\author{
Ilknur Erdem ${ }^{a}$ d Naz Oguzoglu ${ }^{b}$ Derya Ozturk Engin ${ }^{a}$ Asu Ozgultekin ${ }^{c}$ \\ Asuman Sengoz Inan ${ }^{a}$ Nurgul Ceran ${ }^{a}$ Fatma Kaya ${ }^{b}$ Ipek Genc ${ }^{a}$ Pasa Goktas ${ }^{a}$ \\ ${ }^{a}$ Clinic of Infectious Disease, ${ }^{b}$ Clinical Microbiology Laboratory and ${ }^{c} C l i n i c$ of Intensive Care Medicine, \\ Haydarpasa Numune Hospital, Istanbul, and d Department of Infectious Disease and Clinical Microbiology, \\ Faculty of Medicine, Namik Kemal University, Tekirdag, Turkey
}

\section{Key Words}

Nosocomial candidemia $\cdot$ Incidence $\cdot$ Etiology $\cdot$ Mortality

\begin{abstract}
Objective: The aim of this study was to determine the incidence, etiology and risk factors for mortality of patients with nosocomial candidemia. Subjects and Methods: This observational study was performed at Haydarpasa Numune Training and Research Hospital, a tertiary care hospital with 750 beds, between the years 2004 and 2007. Fifty defined cases with a nosocomial bloodstream infection caused by Candida species were included in the study. All demographic, microbiological and clinical records for each patient were collected using a standardized form. Blood culture was performed by automated blood culture system, and those samples positive for yeast were subcultured on Sabouraud agar. Results: The mean incidence density of nosocomial candidemia was $0.58 / 10,000$ patient-days/year (range 0.17-1.4). Candidemia episodes increased from $0.17 / 10,000$ to $1.4 / 10,000$ patientdays/year $(p<0.0001)$. Candida albicans and non-albicans Candida accounted for 15 (30\%) and 35 (70\%) cases, respectively. The overall mortality was $56 \%$ and was significantly associated with staying in the intensive care unit (odds ratio:
\end{abstract}

3.667, 95\% confidence interval: $1.07-12.54, p=0.034)$. Conclusion: This study showed that there was a significantly increased trend in the incidence of candidemia with high mortality during the study period. Copyright $\odot 2010$ S. Karger AG, Basel

\section{Introduction}

Candida species are the fourth most commonly isolated pathogens in patients with nosocomial bloodstream infections in the USA with similar trends reported worldwide, accounting for $8-10 \%$ of all bloodstream infections $[1,2]$. The incidence of nosocomial candidemia is increasing in many hospitals $[1,3]$. Candidemia is associated with prolonged hospital stay and high rates of morbidity and mortality. Critically ill patients are at particular risk for candidemia. According to the surveillance study reports, $25-50 \%$ of these infections occur among patients in intensive care units [4]. Intravascular catheters, broad-spectrum antibiotic therapy, previous surgical procedures, total parenteral nutrition, mucosal colonization, neutropenia and concomitant bacteremia are well-known possible risk factors for invasive Candida

\section{KARGER}

Fax +41 613061234

E-Mail karger@karger.ch

www.karger.com
(C) 2010 S. Karger AG, Basel

1011-7571/10/0196-0463\$26.00/0

Accessible online at:

www.karger.com/mpp
Assoc. Prof. Ilknur Erdem

Namik Kemal University, Faculty of Medicine

Department of Infectious Disease and Clinical Microbiology

TR-59100 Tekirdag (Turkey)

Tel./Fax +90282 2636838 , E-Mail ierdem@nku.edu.tr 
Table 1. Distribution of candidemia by years

\begin{tabular}{|c|c|c|c|c|c|c|c|c|c|c|}
\hline & \multicolumn{2}{|c|}{2004} & \multicolumn{2}{|c|}{2005} & \multicolumn{2}{|c|}{2006} & \multicolumn{2}{|c|}{2007} & \multicolumn{2}{|c|}{ Total } \\
\hline & $\mathrm{n}$ & ratio & $\mathrm{n}$ & ratio & $\mathrm{n}$ & ratio & $\mathrm{n}$ & ratio & $\mathrm{n}$ & ratio \\
\hline Incidence, $n / 10,000$ patient-days/year & 4 & 0.23 & 4 & 0.17 & 11 & 0.46 & 31 & 1.4 & 50 & 0.58 \\
\hline Candida albicans & 1 & $25 \%$ & 1 & $25 \%$ & 2 & $18 \%$ & 11 & $35 \%$ & 15 & $30 \%$ \\
\hline Non-albicans Candida & 3 & $75 \%$ & 3 & $75 \%$ & 9 & $82 \%$ & 20 & $65 \%$ & 35 & $70 \%$ \\
\hline
\end{tabular}

infections [5-7]. In this study, the incidence, etiology and risk factors associated with mortality for nosocomial candidemia were evaluated during a 4-year period in a teaching hospital.

\section{Subjects and Methods}

\section{Study Design}

This observational study was conducted at Haydarpasa Numune Training and Research Hospital, Istanbul, Turkey, a tertiary care teaching hospital with 750 beds, between the years 2004 and 2007. A medical-surgical intensive care unit with 21 beds was established in 2006; previously, the intensive care unit had had only 12 beds in 2004 and 2005. An infection control nurse and an infectious disease specialist evaluated the patients by active surveillance methods. All demographic, microbiological and clinical data of the patients with nosocomial candidemia were obtained from medical records and were entered into standard data collection forms. Two cases with polymicrobial candidemia were excluded. Death was considered to be attibutable to candidemia if there was no other suspected cause for death. Blood culture was performed by automated blood culture system (Bactec 9240). Blood cultures that were positive for yeasts were subcultured on Sabouraud dextrose agar (Oxoid). The identification of Candida species was done by germ tube and biochemical testing using the ID 32C system (bioMérieux, France).

\section{Definition}

Nosocomial candidemia was defined as the presence of positive blood culture for Candida species in at least 1 blood culture sample using traditional microbiological procedures if they occurred $\geq 48 \mathrm{~h}$ after hospital admission with concomitant signs and symptoms of infection according to the criteria of the Centers for Disease Control and Prevention [8]. Incidence density was defined as the number of nosocomial candidemia per 10,000 patient-days.

\section{Statistical Analysis}

Statistical analysis of data was performed using the NCSS 2007 and PASS 2008 Statistical Software (Utah, USA) programs. The $\chi^{2}$ test and Fisher's exact test were used to evaluate the association between categorical quantitative variables. The changes in the incidence rates and distribution of the nosocomial candidemia were analyzed by the $\chi^{2}$ test for trend. Univariate analyses were per- formed to identify risk factors associated with mortality. The odds ratio with $95 \%$ confidence interval was calculated. A p value of less than 0.05 was considered to be statistically significant. A $\mathrm{p}$ value of less than 0.001 was considered to be highly statistically significant.

\section{Results}

During the 4-year study period, a total of 50 episodes of nosocomial candidemia were identified, with an average incidence of 4.23/10,000 discharged (range 1.37-10.5) and an average incidence density of 0.58 episodes $/ 10,000$ patient-days/year (range 0.17-1.4) as shown in table 1 . Candidemia episodes were increased from $0.17 / 10,000$ to $1.4 / 10,000$ patient-days/year $(\mathrm{p}<0.0001)$. Of the 50 episodes, 33 (66\%) occurred in males with a median age of 55.8 years (range 17-87). The average length of hospitalization before the onset of candidemia for nosocomal candidemia was 50.1 days (range 11-266). The mean time required for the detection of growth was 3.44 days (range 2-7 days) in the Bactec 9240 system. Thirty-two (64\%) patients had stayed in the intensive care unit. All patients had taken antibiotic treatment previously; $36(72 \%)$ used 3 or more antibiotics. Forty-six (92\%) patients had central venous catheters, and $41(82 \%)$ had received total parenteral nutrition. The main characteristics of the patients are shown in table 2.

Candida albicans and non-albicans Candida accounted for 15 (30\%) and 35 (70\%) episodes, respectively. The species of non-albicans Candida was identified in only 17 (48\%) isolates because we began to specify strains after 2006. These included Candida tropicalis (7), Candida parapsilosis (4), Candida glabrata (3) and Candida kefyr (3). During the 4-year study period, no significant changes were observed in the distribution of Candida species $(\mathrm{p}=0.7361)$.

Twenty-six (52\%) patients received antifungal therapy for an average of 18 days (range 12-34). Twenty-four patients were not treated with antifungal drugs because of 
the delay in obtaining blood culture results and clinical diagnosis. The overall mortality rate was 56\% (28/50); it was $47 \%(7 / 15)$ and $60 \%(21 / 35)$ for C. albicans and nonalbicans Candida species, respectively. The results of univariate analysis of risk factors for mortality are summarized in table 3. Staying in the intensive care unit (odds ratio: 3.667; 95\% confidence interval: $1.07-12.54$; $\mathrm{p}=$ 0.034 ) was significantly associated with mortality. In patients having nosocomial candidemia, staying in the intensive care unit increased the mortality rate by 3.6 times. The presence of a central venous catheter was not significantly associated with mortality because a central venous catheter and a urinary catheter were used in all these patients.

\section{Discussion}

The mean incidence density of nosocomial candidemia was 0.58 episodes/10,000 patient-days/year, and this represented a 6 -fold increase in the incidence of candidemia in comparison with the period 2004-2007 probably due to excessive use of antibiotics and indwelling devices in our hospital as previously reported [9].

The epidemiology of candidemia may vary depending on geographic locations, even between units in the same hospital. Although C. albicans has been the predominantly isolated species, there has been a shift in the distribution to the non-albicans Candida species as reported
Table 2. Characteristics of the patients

\begin{tabular}{|c|c|c|}
\hline Variable & $\begin{array}{l}\text { Number of } \\
\text { episodes }\end{array}$ & $\begin{array}{l}\text { Percent } \\
(n=50)\end{array}$ \\
\hline \multicolumn{3}{|l|}{ Gender } \\
\hline Male & 33 & 66 \\
\hline Female & 17 & 34 \\
\hline \multicolumn{3}{|l|}{ Admitting ward } \\
\hline Surgery & 34 & 68 \\
\hline Medicine & 15 & 30 \\
\hline Intensive care unit & 32 & 64 \\
\hline \multicolumn{3}{|l|}{ Associated conditions } \\
\hline Previous antibiotic treatment & 50 & 100 \\
\hline Previous intra-abdominal surgery & 22 & 44 \\
\hline Diabetes mellitus & 11 & 22 \\
\hline Malignancy & 4 & 8 \\
\hline Pancreatitis & 2 & 4 \\
\hline Cardiovascular disease & 3 & 6 \\
\hline Trauma & 9 & 18 \\
\hline Immunosuppression & 0 & 0 \\
\hline Chronic obstructive lung disease & 1 & 2 \\
\hline Transplantation & 0 & 0 \\
\hline Neutropenia & 1 & 2 \\
\hline \multicolumn{3}{|l|}{ Applied procedure } \\
\hline Central venous catheter & 46 & 92 \\
\hline Total parenteral nutrition & 41 & 82 \\
\hline Urinary catheter & 47 & 94 \\
\hline \multicolumn{3}{|l|}{ Laboratory results } \\
\hline Leukocytosis & 18 & 36 \\
\hline Thrombocytopenia & 16 & 32 \\
\hline Increase in liver enzyme level & 19 & 38 \\
\hline Increase in serum creatinine level & 11 & 22 \\
\hline Candiduria & 21 & 42 \\
\hline
\end{tabular}

Table 3. Univariate analysis of risk factors associated with mortality

\begin{tabular}{|c|c|c|c|c|c|}
\hline Age & $58.18 \pm 20.31$ & $58.82 \pm 17.65$ & 0.907 & - & \\
\hline Male & $17(60.7)$ & $16(72.3)$ & 0.373 & - & \\
\hline Presence of central venous catheters & $28(100)$ & $18(81.8)$ & $0.032 *$ & - & \\
\hline Presence of urinary catheters & $28(100)$ & $19(86.4)$ & 0.079 & - & \\
\hline Hyperalimentation & $24(85.7)$ & $17(77.3)$ & 0.441 & 1.765 & $0.41-7.55$ \\
\hline Late initial therapy & $5(29.4)$ & $4(44.4)$ & 0.443 & 0.521 & $0.09-2.79$ \\
\hline Staying in intensive care unit & $22(78.6)$ & $11(50.0)$ & $0.034^{*}$ & 3.667 & $1.07-12.54$ \\
\hline Thrombocytopenia & $10(35.7)$ & $6(27.3)$ & 0.525 & 1.481 & $0.43-4.99$ \\
\hline Non-albicans Candida & $19(67.9)$ & $16(72.7)$ & 0.709 & 0.792 & $0.23-2.72$ \\
\hline Intra-abdominal operation & $14(50.0)$ & $8(36.4)$ & 0.335 & 1.750 & $0.55-5.48$ \\
\hline
\end{tabular}

$\mathrm{p}$ values assessed by Student's t test; ${ }^{*} \mathrm{p}<0.05$. Figures in parentheses indicate percentages. OR $=\mathrm{Odd}$ ratio; CI $=$ confidence interval. 
previously [10-12] and confirmed in our study as the proportion of non-albicans Candida species was 70\%. However, this is higher than the previous report of $66 \%$ by Bakir et al. [13]. The difference could be due to the frequent use of fluconazole in our hospital.

Generally, candidemia is associated with high morbidity and mortality despite antifungal treatment. Independent risk factors associated with mortality in patients with candidemia have been reported in various studies [14-18]. Included in the risk factors are advanced age and high scores of the Acute Physiology and Chronic Health Evaluation (APACHE) II [14], or bacterial sepsis, rapidly fatal illness, chronic obstructive lung disease, presence of a central venous catheter and lack of antifungal therapy [15]; impaired general condition performance status, low serum albumin, congestive heart failure and shock were independent factors associated with mortality. Inadequate initial therapy and high APACHE III scores [16] were other risk factors, and fungemia itself [17] had a 5-fold higher mortality rate in patients with fungemia in comparison to others. However, Barberino et al. [19] showed that there was no difference in the mortality between cases and controls. They suggested that severity of the underlying disease was a better risk factor of mortal- ity. Gudlaugsson et al. [20] did not report any statistically significant differences in age, sex, underlying disease, surgical procedure or vital signs at admission between cases and controls either. The crude mortality rate among cases did not differ significantly by Candida species either. Some non-albicans Candida species had been associated with a poorer prognosis [21, 22]. Further, Viscoli et al. [22] reported that patients with both candidemia and cancer had a poorer clinical outcome. The high mortality rate of $56 \%$ in our study confirmed the previous findings described above. In the univariate analysis, the parameter that was independently associated with mortality was staying in the intensive care unit.

\section{Conclusion}

Our study showed that candidemia was associated with a high mortality rate and staying in the intensive care unit was an associated risk factor. There was a significantly increased trend in the incidence of candidemia during the study period most probably due to antibiotic overuse, inadequate infection control and prevention program in our hospital.

\section{References}

1 Wisplinghoff $\mathrm{H}$, Bischoff T, Tallent SM, Seifert H, Wenzel RP, Edmond MB: Nosocomial bloodstream infections in US hospitals: analysis of 24,179 cases from a prospective nationwide surveillance study. Clin Infect Dis 2004;39:309-317.

2 Ostrosky-Zeichner L: New approaches to the risk of Candida in the intensive care unit. Curr Opin Infect Dis 2003;16:533-537.

3 Pfaller MA, Diekema DJ: Epidemiology of invasive candidiasis: a persistent public health problem. Clin Microbiol Rev 2007;20: 133-163.

4 Bouza E, Munoz P: Epidemiology of candidemia in intensive care units. Int $J$ Antimicrob Agents 2008;32(suppl 2):S87-S91.

$\checkmark 5$ Trick WE, Fridkin SK, Edwards JR, Hajjeh RA, Gaynes RP, National Nosocomial Infections Surveillance System Hospitals: Secular trend of hospital-acquired candidemia among intensive care unit patients in the United States during 1989-1999. Clin Infect Dis 2002;35:627-630.
6 Rangel-Frausto MS, Wiblin T, Blumberg HM, Saiman L, Patterson J, Rinaldi M, Pfaller M, Edwards JE Jr, Jarvis W, Dawson J, Wenzel RP: National epidemiology of mycoses survey (NEMIS): variations in rates of bloodstream infections due to Candida species in seven surgical intensive care units and six neonatal intensive care units. Clin Infect Dis 1999;29:253-258.

7 Yapar N, Uysal U, Yucesoy M, Cakir N, Yuce A: Nosocomial bloodstream infections associated with Candida species in a Turkish University Hospital. Mycoses 2006;49:134138.

-8 Garner JS, Jarvis WR, Emori TG, Horan TC, Hughes JM: CDC definitions for nosocomial infections. Am J Infect Control 1998;16:128140.

-9 Erdem I, Ozgultekin A, Sengoz Inan A, Ozturk Engin D, Senbayrak Akcay S, Turan G, Dincer E, Oguzoglu N, Goktas P: Bloodstream infections in a medical-surgical intensive care unit: incidence, aetiology, antimicrobial resistance patterns of Grampositive and Gram-negative bacteria. Clin Microbiol Infect 2009; 15:943-946.
10 Marchetti O, Bille J, Fluckiger U, Eggimann P, Ruef C, Garbino J, Calandra T, Glauser MP, Tauber MG, Pittet D, Fungal Infection Network of Switzerland: Epidemiology of candidemia in Swiss tertiary care hospitals: secular trends, 1991-2000. Clin Infect Dis 2004;38:311-320.

11 Bassetti M, Righi E, Costa A, Fasce R, Molinari MP, Rosso R, Pallavicini FB, Viscoli C: Epidemiological trends in nosocomial candidemia in intensive care. BMC Infect Dis 2006;6:21.

12 Richet H, Roux P, Des Champs C, Esnault Y, Andremont A, French Candidemia Study Group: Candidemia in French hospitals: incidence rates and characteristics. Clin Microbiol Infect 2002;8:405-412.

13 Bakir M, Cerikcioglu N, Barton R, Yagci A: Epidemiology of candidemia in a Turkish tertiary care hospital. APMIS 2006;114:601610 
14 Colombo AL, Guimaraes T, Silva LR, de Almeida Monfardini LP, Cunha AK, Rady P, Alves T, Rosas RC: Prospective observational study of candidemia in Sao Paulo, Brazil: incidence rate, epidemiology, and predictors of mortality. Infect Control Hosp Epidemiol 2007;28:570-576.

15 Alonso Valle H, Acha O, Garcia Palomo JD, Farinas-Alvarez C, Fernandez-Mazarrasa C, Farinas MC: Candidemia in a tertiary care hospital: epidemiology and factors influencing mortality. Eur J Clin Microbiol Infect Dis 2003;22:254-257.

16 Weinberger M, Leibovici L, Perez S, Samra Z, Ostfeld I, Levi I, Bash E, Turner D, Goldschmied-Reouven A, Regev-Yochay G, Pitlik SD, Keller N: Characteristics of candidemia with $C$. albicans compared with non-albicans Candida species and predictors of mortality. J Hosp Infect 2005;61:146-154.
Bassetti M, Trecarichi EM, Righi E, Sanguinetti M, Bisio F, Posteraro B, Soro O, Cauda R, Viscoli C, Tumbarello M: Incidence, risk factors, and predictors of outcome of candidemia: survey in 2 Italian university hospitals. Diagn Microbiol Infect Dis 2007;58: 325-331.

18 Eryuksel E, Ergonul O, Olgun S, Odabasi Z, Korten V, Celikel T: Risk factors for mortality in fungal infections. Turkiye Klinikleri J Med Sci 2009;1:99-103.

19 Barberino MG, Silva N, Reboucas C, Barreiro K, Alcantara AP, Netto EM, Albuquerque L, Brites C: Evaluation of blood stream infections by Candida in three tertiary hospitals, in Salvador, Brazil: a case-control study. Braz J Infect Dis 2006;10:36-40.

20 Gudlaugsson O, Gillespie S, Lee K, Vande Berg J, Hu J, Messer S, Herwaldt L, Pfaller M, Diekema D: Attributable mortality of nosocomial candidemia, revisited. Clin Infect Dis 2003;37:1172-1177.
21 Dimopoulos G, Ntziora F, Rachiotis G, Armaganidis A, Falagas ME: Candida albicans versus non-albicans intensive care unit-acquired bloodstream infections: differences in risk factors and outcome. Anesth Analg 2008;106:523-529.

-22 Viscoli C, Girmenia C, Marinus A, Collette L, Martino P, Vandercam B, Doyen C, Lebeau B, Spence D, Krcmery V, De Pauw B, Meunier F: Candidemia in cancer patients: a prospective, multicenter surveillance study by the Invasive Fungal Infection Group (IFIG) of the European Organisation for Research and Treatment of Cancer (EORTC). Clin Infect Dis 1999;28:1071-1079. 